\title{
Starving with a full gut? Effect of suspended particles on the fitness of Daphnia hyalina
}

\section{Conference Paper}

\section{Author(s):}

Rellstab, Christian; Spaak, Piet

Publication date:

2007

Permanent link:

https://doi.org/10.3929/ethz-b-000018796

Rights / license:

In Copyright - Non-Commercial Use Permitted

Originally published in:

Hydrobiologia 594(1), https://doi.org/10.1007/s10750-007-9089-y 


\title{
Starving with a full gut? Effect of suspended particles on the fitness of Daphnia hyalina
}

\author{
Christian Rellstab $\cdot$ Piet Spaak
}

(C) Springer Science+Business Media B.V. 2007

\begin{abstract}
Suspended particles are abiotic factors that can affect the abundance of cladocerans such as daphnids. Ultra-oligotrophic Lake Brienz, situated in the front ranges of the Swiss Alps, is dominated by two major inflows that annually transport over 300,000 tons of suspended glacial material into the lake. A laboratory flow-through experiment was performed to test whether these suspended particles have an influence on the fitness of Daphnia hyalina from Lake Brienz, measured as body size, fecundity and juvenile growth rate, especially when they are simultaneously exposed to low food concentrations. Our results show that the concentration of suspended particles present in Lake Brienz does not reduce the fitness of daphnids, even at very low food concentration. In fact, a low concentration of suspended particles increased the fitness. Reduction of fitness could only be observed at a
\end{abstract}

Guest editor: Piet Spaak

Cladocera: Proceedings of the 7th International Symposium on Cladocera

C. Rellstab $(\varangle) \cdot$ P. Spaak

Eawag, Swiss Federal Institute of Aquatic Science

and Technology, Dübendorf 8600, Switzerland

e-mail: rellstab@eawag.ch

P. Spaak

e-mail: spaak@eawag.ch

C. Rellstab · P. Spaak

Institute of Integrative Biology, ETH Zürich,

Zürich 8092, Switzerland suspended particle concentration of over $25 \mathrm{mg} \mathrm{l}^{-1}$, a level that has never been recorded in Lake Brienz.

Keywords Lake Brienz - Daphnia hyalina . Ultra-oligotrophic · Fitness · Food ·

Suspended particles

\section{Introduction}

Deep ultra-oligotrophic, pre-alpine lakes present a harsh environment for biological production. Water temperature is low for most of the year and slows biological processes. These lakes are often protected from wind by surrounding mountains, which, in combination with a deep water column, reduces mixing activity (Lampert \& Sommer, 1999). Thus, few nutrients are re-released into the epilimnion where they can be used by the photosynthesizing algal community. If the lake is also influenced by rivers that originate from glacial regions, another factor affects the system: glacier water transports a large amount of inorganic suspended material, whose characters depend on the catchment geology. This material can have several effects on organisms as it changes the physical and chemical parameters of the water (like conductivity, specific weight, $\mathrm{pH}$ and light transmission) and thus influences the entire ecosystem. Reduced light transmission is the most influential factor on the food chain in lakes, decreasing phytoplankton biomass and productivity (Jewson \& 
Taylor, 1978; Krause-Jensen \& Sand-Jensen, 1998). Inorganic suspended particles can also bind to nutrients (Müller et al., 2006) and prevent them from being used for primary production. The combination of low water temperatures, low nutrient input and high concentrations of inorganic suspended material makes this type of lake very unproductive and normally is favourable for copepods and rotifers rather than for cladocerans, at least in winter (e.g., Adalsteinsson, 1979; Kirk \& Gilbert, 1990).

Daphnia are major herbivores in many lakes as well as in small ponds and play an important role in the aquatic food web (e.g., Manca \& Ruggiu, 1998). They link the primary production of planktonic algae with vertebrate predators like planktivorous fish. Laboratory and in situ feeding experiments have demonstrated that, in general, daphnids ingest particles in a size range of $0.5-40 \mu \mathrm{m}$. As they are filter feeders, they ingest particles in proportion to their abundance in the environment (Demott, 1982). Cladocerans ingest inorganic suspended particles because their food-size niches overlap the range of suspended particles sizes commonly found in nature (Arruda et al., 1983; Gliwicz, 1986).

Several field studies have revealed an inverse relationship between the abundance of planktonic cladocera or even total zooplankton biomass and suspended particle concentration (e.g., Hart, 1986; Zettler \& Carter, 1986; Hart, 1987; Koenings et al., 1990). In some cases (e.g., Zurek, 1980; Koenings et al., 1990), when the concentration of suspended particles was particularly high, cladocerans were even totally absent. Most of these studies were done on small and shallow lakes, where turbidity originates from the re-suspended lake sediment. Only few researchers (Zurek, 1980; Zettler \& Carter, 1986; Koenings et al., 1990) have addressed the importance of inorganic material coming from glacial or mountain rivers.

Many laboratory studies have examined the effect of suspended particles, by exposing daphnids or other cladocerans to different kinds of inorganic material, which differ in particle size distribution and chemical composition. These studies could show that natural concentrations of suspended particles can reduce the ingestion rate, fecundity, survival, fitness and population growth rates of cladocerans (e.g., Zurek, 1982; Arruda et al., 1983; McCabe \& O'Brien, 1983; Kirk, 1992; Bozelli, 1998), especially when simultaneously exposed to low algae concentrations. In most cases the threshold concentration of suspended particles at which negative effects started to occur was $50 \mathrm{mg}^{-1}$ or higher. Only Bozelli (1998) and McCabe \& O'Brien (1983) could show a decrease in carbon ingestion rate or assimilation efficiency at lower concentrations. There seems to be large variation in responding to suspended particles, depending on the particle type (Kirk \& Gilbert, 1990; Kirk, 1991a) and cladoceran species (Arruda et al., 1983; Kirk \& Gilbert, 1990). The inhibitory effects of inorganic suspended material on cladocerans is caused primarily by a decrease in the ingestion rate of nutritious phytoplankton cells (Adalsteinsson, 1979; Zurek, 1982; Arruda et al., 1983; McCabe \& O’Brien, 1983; Bozelli, 1998) rather than by a direct impact of the particles itself.

Interestingly, low concentrations of suspended particles, in combination with low food levels, sometimes increased population growth and reproduction rate of daphnids (Robinson, 1957; Kirk \& Gilbert, 1990; Hart, 1992). High concentration of inorganic suspended particles can also have a positive effect on daphnids as it leads to reduced water transparency and therefore to a reduced predation pressure from visually hunting planktivorous fish (Vinyard \& O’Brien, 1976; Carvalho, 1984). Daphnids in turbid lakes can be larger than daphnids in comparable lakes without turbidity (McCabe \& O'Brien, 1983; Zettler \& Carter, 1986). Another positive effect of high concentration of suspended particles is their ability to reduce the bioavailability of organic hydrophobic toxicants (e.g., McCarthy, 1983) caused primarily by sorption to organic carbon (Chiou et al., 1979).

Ultra-oligotrophic Lake Brienz (SRP $=0.9 \mu \mathrm{g}^{-1}$; $P_{\text {tot }}=3.0 \mu \mathrm{g} \mathrm{l}^{-1}$ ), situated in the front ranges of the Swiss Alps at $564 \mathrm{~m}$ a.s.1 (maximum depth $259 \mathrm{~m}$, area $30 \mathrm{~km}^{2}$ ), is dominated by two major inflows, the rivers Aare and Lütschine. These rivers transport annually over 300,000 tons of suspended material into the lake (Finger et al., 2006). Only 3\% of this suspended material is transported through the outflow, while the rest sediments into the lake. The Lütschine catchment is mostly composed of limestone, whereas the Aare has primarily a crystalline geology (Sturm \& Matter, 1978). Investigations Finger et al. (2006) show a maximum concentration of suspended particles of $24 \mathrm{mg} \mathrm{l}^{-1}$ (dry weight) in 
the upper layer of the lake in late August and early September, whereas normal concentrations were only 4-8 $\mathrm{mg} \mathrm{l}^{-1}$ in summer and $1-3 \mathrm{mg} \mathrm{l}^{-1}$ in winter. Epilimnetic temperatures in the lake reach $17-20^{\circ} \mathrm{C}$ in summer.

We hypothesized that a high concentration of suspended particles, in combination with low food concentrations, decreases the fitness of Daphnia hyalina. To test this hypothesis, we performed a laboratory experiment where we exposed daphnids to various combinations of algae and suspended particle concentrations. The obtained results are then related to the actual conditions in the lake and their consequences for the Daphnia population.

\section{Material and methods}

According to Müller-Navarra \& Lampert (1996), POC (particulate organic carbon) concentration is the most realistic way of measuring food quantity (others include biovolume, levels of chlorophyll, nitrogen or proteins). In order to quantify the food conditions of daphnids in Lake Brienz, water samples at depths of $0,2,4,6,8,10,15,20,30$ and $40 \mathrm{~m}$ were taken in the centre of the lake with a Friedinger water sampler. Sampling was performed at least monthly between September 2004 and October 2005. From these samples, POC concentrations were determined (combustion at $880^{\circ} \mathrm{C}$ and subsequent measurement of the generated $\mathrm{CO}_{2}$ with a Horiba IR-detector).

A clonal culture of D. hyalina, the most abundant taxon in Lake Brienz found in 2003-2005 (Christian Rellstab, unpublished data), was maintained in the laboratory at $20^{\circ} \mathrm{C}$ in filtered $(0.45 \mu \mathrm{m})$ lake water from non-turbid Lake Greifensee. 100-150 animals

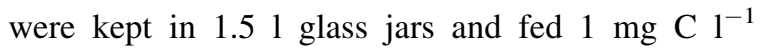
(chemostat grown Scenedesmus obliquus) three times a week. Starting 2 weeks before the experiment, animals were fed daily. In order to obtain juveniles of nearly equal size and age, individuals born within $24 \mathrm{~h}$ were used for the experiment. At the start of the experiment, 40 juveniles were randomly chosen and body size, from the base of the spine to the top of the eye, and dry weight (in groups of five animals) were determined.

We used a flow-through system to perform the feeding experiment. For each experimental unit, five animals were placed in $150 \mathrm{ml}$ Perspex cylinders (containing $132 \mathrm{ml}$ of water) closed with plankton gauzes (mesh size $150 \mu \mathrm{m}$ ). Exchange rate was 10 times the water volume per day. The cylinders were distributed randomly in two water baths in a temperature controlled room at $20^{\circ} \mathrm{C}$ under constant light:dark regime of 16:8 h. The experiment lasted for 6 days. For each algae and particle concentration, a medium at double concentration was prepared daily in a 101 glass bottle. Every cylinder was connected to two media, one for the algae and one for the particles. The media in the reservoir bottles were stirred and aerated continuously and kept in the dark. Four different algae (chemostat-grown Scenedesmus obliquus) and five different particle concentrations were combined and replicated three times (60 experimental units). The following concentrations of algae were used: 0.0 (no algae), 0.1 (winter situation), 0.4 (summer) and $1 \mathrm{mg} \mathrm{C}^{-1}$ ("ad libitum"). Concentrations of suspended particles were: 0 (no particles), 5 (normal), 10 (high), 25 (floods) and $100 \mathrm{mg} \mathrm{l}^{-1}$ ("ad libitum"). Glass bottles containing the media were washed daily and autoclaved every second day. At the end of the experiment, the following parameters were measured: mortality, body size, dry weight (average per experimental unit) and fecundity (clutch size). From the increase in the dry weight, the juvenile growth rate (Lampert \& Trubetskova, 1996) was calculated.

Dry material of suspended particles was prepared from a sediment core taken in the bay of Iseltwald, Lake Brienz, in March 2004, at $20 \mathrm{~m}$ depth. This location was chosen as the sediment is consisting of particles from both inflows. Former investigations showed that it is composed of apatite, epidote and hornblende (Sturm, 1976). It is virtually carbonate free, contains no sand-sized particles and its mean grain size lies within the fine silt grade (Sturm \& Matter, 1978). The material was autoclaved and then freeze dried. The dry sediment was weighed daily, mixed with filtered lake water and put in an ultrasonic bath. After sieving it through a $45-\mu \mathrm{m}$ net, the solution was connected to the flow-through system. Subsamples of the particle media were taken and particle size distribution was measured by static light scattering and polarization intensity differential scattering (PIDS) using a Beckman Coulter LS 230 instrument. The POC concentration was determined in order to quantify the organic proportion of the sediment. 
The arc-sine-square-root transformed mortality data were analyzed using a 2-way ANOVA, with the algae (POC) concentration and the suspended particle concentration used as fixed factors. The effects of the treatments on the three measured life history characters (body size, juvenile growth rate and fecundity) were first analyzed as a MANOVA (as they are not independent), with subsequent 2-way ANOVAs (factors: POC concentration, suspended particle concentration) on experimental unit means (significance threshold $p \leq 0.05$ ). Tuckey's post hoc tests were used to distinguish among treatments. All statistical analyses were performed using SPSS (version 11.0).

\section{Results}

The POC concentrations in the lake ranged from 0.03 (21 December 2004, lake surface) to 0.53 (29 June 2005, $4 \mathrm{~m} \mathrm{depth)} \mathrm{mg} \mathrm{C}^{-1}$. Average POC concentration of the upper $30 \mathrm{~m}$ was $0.20-0.38 \mathrm{mg} \mathrm{C}^{-1}$ in late spring and summer (May to September) and 0.04-0.16 mg C $1^{-1}$ in the rest of the year (Fig. 1). Highest POC concentrations were normally found at

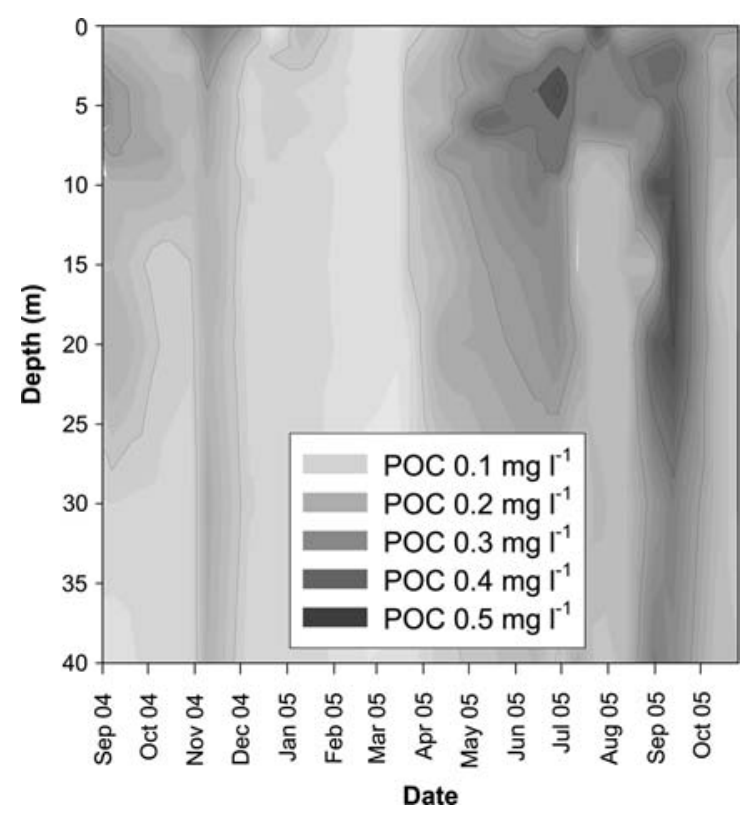

Fig. 1 Contour plot of the POC concentrations of Lake Brienz at different depths from September 2004 to October 2005. Grey scales and lines indicate different POC concentrations a depth of $4 \mathrm{~m}$. After heavy rainfall or floods, POC concentrations increased throughout the 40-m water column that was measured (e.g., November 2004 and August/September 2005). These POC concentrations served as a basis for the POC treatments chosen for the experiment.

The particle size range was $0.1-40 \mu \mathrm{m}$, with particles of $0.2 \mu \mathrm{m}$ being the most abundant and particles of 0.3 and $3.0 \mu \mathrm{m}$ having the largest proportions in terms of volume. This size distribution is similar to the distribution found in open water lake samples. The sediment contained $1 \%$ of organic material.

The 2-way ANOVA showed no effect of POC concentration $\left(F_{3,40}=0.33, P=0.804\right)$, and suspended particle concentration $\left(F_{4,40}=1.017, P=0.410\right)$ nor its interaction $\left(F_{12,40}=1.847, P=0.073\right)$ on mortality after six experimental days. Mortality in treatments showed high variation (0-46\%) and no clear pattern. Average overall mortality was $19 \%( \pm 2.8 \%$ standard error). Nevertheless, in those treatments with the highest suspended particle concentration $\left(100 \mathrm{mg} \mathrm{l}^{-1}\right)$, mortality was high $(40 \%)$ in the no food treatment, intermediate (13-26\%) in the medium food treatments and absent $(0 \%)$ in the highest food concentration.

The MANOVA (Table 1), analyzing the overall effect of the fixed factors on the three dependent response characters, showed that POC and suspended particle concentration and its interaction had a significant effect on the three measured life history characters of Daphnia. Subsequent univariate analyses (Table 1) showed that POC and suspended particle concentration and its interaction had a significant effect on all response variables, except that the interaction had no significant influence on the juvenile growth rate.

Body size increased with higher POC concentrations (Fig. 2). Tuckey's post hoc test confirmed this finding, though there was no significant difference between the 0.4 and $1.0 \mathrm{mg} \mathrm{C} \mathrm{l}^{-1}$ treatments (Table 2). Body size increased with low suspended particle concentration, reached its maximum at $25 \mathrm{mg}^{-1}$ and then decreased at the maximum suspended particle level on all food treatments. The latter effect was especially pronounced in the treatment with $0.1 \mathrm{mg} \mathrm{C}^{-1}$. Tuckey's post hoc test found no significant differences in the influence of suspended particle concentration of 5, 10 and $100 \mathrm{mg}^{-1}$, but body size was significantly lower 
Table 1 Summary of the multivariate (MANOVA) and subsequent univariate analyses (2-way ANOVA) for body size, juvenile growth rate and fecundity (clutch size) of Daphnia hyalina at the end of the feeding experiment

\begin{tabular}{|c|c|c|c|c|c|c|c|}
\hline Analysis & Dependent variable & Source & Wilks' $\lambda$ & $\mathrm{df}$ & Type III sum of squares & $F$ & $P$ \\
\hline \multirow[t]{3}{*}{ MANOVA } & & POC & 0.192 & 9,92 & & 10.002 & 0.000 \\
\hline & & SP & 0.345 & 12,101 & & 4.162 & 0.000 \\
\hline & & $\mathrm{POC} \times \mathrm{SP}$ & 0.299 & 36,113 & & 1.583 & 0.036 \\
\hline \multirow[t]{12}{*}{ 2-way ANOVA } & Body size & $\mathrm{POC}$ & & 3 & 0.279 & 45.683 & 0.000 \\
\hline & & SP & & 4 & 0.082 & 23.328 & 0.000 \\
\hline & & $\mathrm{POC} \times \mathrm{SP}$ & & 12 & 0.022 & 30.371 & 0.000 \\
\hline & & Error & & 40 & 0.006 & & \\
\hline & Juvenile growth rate & $\mathrm{POC}$ & & 3 & 0.064 & 3.546 & 0.001 \\
\hline & & SP & & 4 & 0.023 & 2.940 & 0.005 \\
\hline & & $\mathrm{POC} \times \mathrm{SP}$ & & 12 & 0.003 & 1.566 & 0.142 \\
\hline & & Error & & 40 & 0.002 & & \\
\hline & Fecundity & $\mathrm{POC}$ & & 3 & 20.171 & 13.454 & 0.000 \\
\hline & & SP & & 4 & 3.579 & 4.139 & 0.007 \\
\hline & & POCxSP & & 12 & 2.542 & 10.932 & 0.000 \\
\hline & & Error & & 40 & 0.865 & & \\
\hline
\end{tabular}

Fixed factors are food (POC) and suspended particle (SP) concentration. Significant terms are highlighted in bold

at $0 \mathrm{mg} \mathrm{l}^{-1}$ and significantly higher at $25 \mathrm{mg} \mathrm{l}^{-1}$. The treatment with most algae and no suspended particles did not result in largest body size; animals from medium food levels were larger.

Juvenile growth rate showed a very similar pattern like body size: as expected, juvenile growth rate was increased with higher food concentrations (Fig. 3). Again, Tuckey's post hoc test did not find any

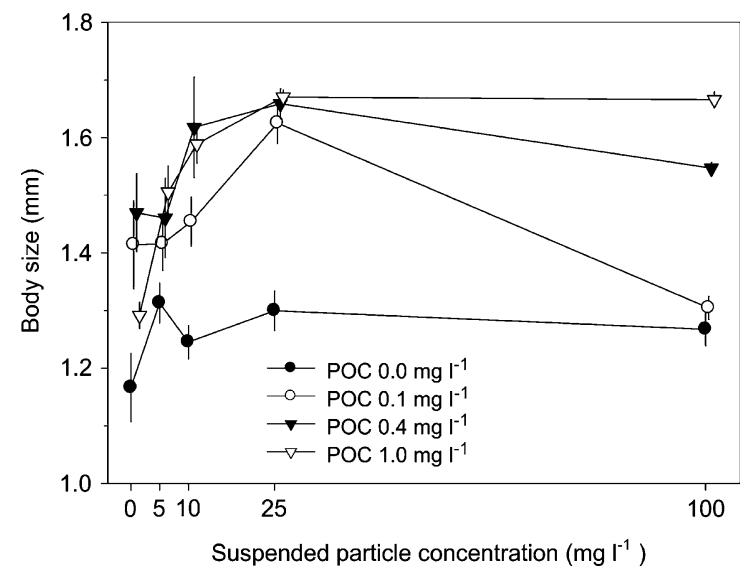

Fig. 2 Influence of particulate organic carbon (POC) and suspended particle concentration on the body size of Daphnia hyalina after six experimental days. Error bars show standard errors significant difference between the 0.4 and $1.0 \mathrm{mg} \mathrm{C} 1^{-1}$ treatments (Table 2). Moderate concentrations of suspended particles had a positive influence on juvenile growth rate. Juvenile growth rate reached its maximum at 10 or $25 \mathrm{mg} \mathrm{l}^{-1}$ and then decreased or stayed the same at $100 \mathrm{mg}^{-1}$ of suspended particles. Juvenile growth rate of the treatment with no food and maximum suspended particle concentration did not decrease comparing to lower suspended particle concentrations.

Fecundity, measured as clutch size, also increased with higher food concentrations (Fig. 4). Again Tuckey's post hoc test confirmed this finding and did not find any significant difference between the 0.4 and $1.0 \mathrm{mg} \mathrm{C}^{-1}$ treatments (Table 2). Suspended particle concentration had a similar effect on fecundity as it did on body size, as fecundity was highest at intermediate concentrations $\left(10-25 \mathrm{mg} \mathrm{l}^{-1}\right)$ of suspended particles. Daphnids that did not receive any algae produced no eggs when exposed to a suspended particle concentration higher than $10 \mathrm{mg}^{-1}$. When suspended particle concentration was low (0$10 \mathrm{mg} \mathrm{l}^{-1}$ ), some of the females produced eggs. Surprisingly, animals with maximum food and no suspended particles produced nearly identical numbers of eggs as animals with no food and no suspended particles. 
Table 2 Summary of Tuckey's post hoc tests to distinguish between the effects of the treatments on the response variables body size, juvenile growth rate and fecundity (clutch size) of Daphnia hyalina

\begin{tabular}{lll}
\hline Response variable & POC & SP \\
\hline Body size & $\underline{0.0}<\underline{0.1}<\underline{0.4<1.0}$ & $\underline{0}<\underline{5<100<10<25}$ \\
Juvenile growth rate & $\underline{0.0}<\underline{0.1}<\underline{0.4<1.0}$ & $\underline{0}<\underline{5<100<10}<25$ \\
Fecundity & $\underline{0.0}<\underline{0.1}<\underline{0.4<1.0}$ & $\underline{0<5<100<10<25}$ \\
\hline
\end{tabular}

Underlined subsets of treatments show no differences. $\mathrm{POC}=$ food concentration, $\mathrm{SP}=$ suspended particle concentration

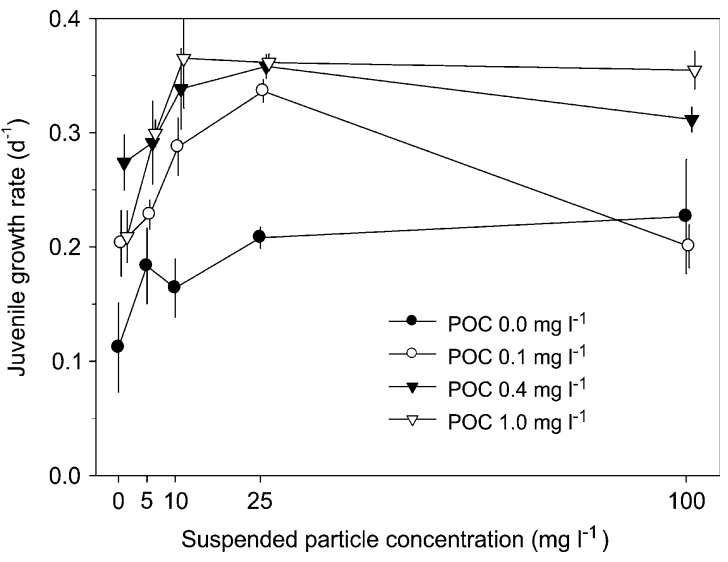

Fig. 3 Influence of particulate organic carbon (POC) and suspended particle concentration on the juvenile growth rate of Daphnia hyalina after six experimental days. Error bars show standard errors

\section{Discussion}

Food in Lake Brienz is scarce for daphnids all year round. From December 2004 to April 2005, POC concentration never exceeded $0.2 \mathrm{mg} \mathrm{C}^{-1}$. Lampert (1977) determined a concentration of $0.05 \mathrm{mg} \mathrm{Cl}^{-1}(D$. pulex fed on Scenedesmus sp.) as the threshold level for maintaining a population in the field. In a later study (Lampert, 1978), adult daphnids (D. longispina group) needed a minimum of $0.2 \mathrm{mg} \mathrm{Cl}^{-1}$ for egg production. Given these facts, a high population density in Lake Brienz is only possible starting early summer (earliest May, average POC concentration $>0.2 \mathrm{mg} \mathrm{C}^{-1}$ ), which is confirmed by quantitative data (Rellstab et al., 2007).

All three life-history response variables (body size, juvenile growth rate and fecundity) responded similarly when daphnids were exposed to different combinations of POC and suspended particle concentrations. A low concentration of suspended particles (5-25 $\mathrm{mg}^{-1}$ ) increased them (with all food

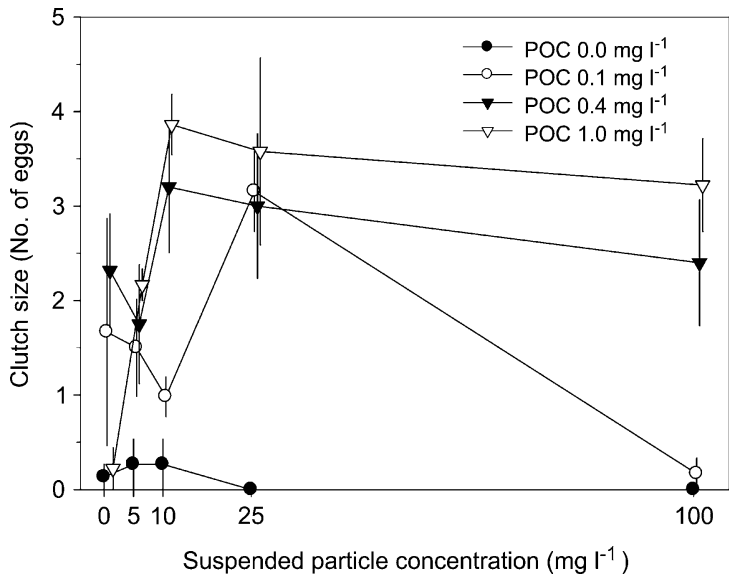

Fig. 4 Influence of particulate organic carbon (POC) and suspended particle concentration on the fecundity (clutch size) of Daphnia hyalina after six experimental days. Error bars show standard errors

treatments), whereas a higher concentration (25-100 $\mathrm{mg} \mathrm{1}^{-1}$ ) decreased them, at least in treatments with a low food concentration $(0.0$ and $0.1 \mathrm{mg} \mathrm{C}^{-1}$ ). There was one exception: juvenile growth rate in the treatment with $0.0 \mathrm{mg} \mathrm{C}^{-1}$ and $100 \mathrm{mg}^{-1}$ suspended particles increased in comparison to the treatments with the same algae but lower suspended particle concentration. Juvenile growth rate is an important fitness measure (Lampert \& Trubetskova, 1996), as it is a robust predictor of the intrinsic rate of population increase (r). In our case, when the suspended particle concentration was high, juvenile growth rate seemed to be a less appropriate measure of fitness: as the animals had a large amount of suspended particles in their guts, the actual weight of the inorganic particles could have biased our measure of the juvenile growth rate, calculated from the dry weights of the animals. Therefore, the values of the juvenile growth rate in the treatments with the 
highest suspended particle concentration should be treated with caution. G-Toth et al. (1986) found that inorganic particles accounted on average for $24 \%$ of the dry weight of $D$. galeata after removal from a highly turbid lake. Increase in body size does not represent an ideal measure for fitness: being large does not mean automatically being fit, as energy could be invested into reproduction instead of size. In contrast, fecundity is a crucial factor for population growth, as the number of eggs has direct consequences for population growth (Paloheimo, 1974).

Surprisingly, all three replicates of the treatment with highest algae concentration and no suspended particles had very low values in all three response variables, being in the range of treatments with very low food concentrations. A problem in the algae medium because of bacteria or because of poor quality can be excluded as the rest of the treatments with highest food level always showed high values in all response variables. Reasons for this phenomenon remain unclear. Regardless, Tuckey's post hoc test did not find any significant difference between the 0.4 and $1.0 \mathrm{mg} \mathrm{C}^{-1}$ treatments in general, indicating that this unexpected outlier actually would be in the same range as the $0.4 \mathrm{mg} \mathrm{C}^{-1}$ treatment.

Many mechanisms have been proposed to account for the decrease in cladoceran algal feeding rates in the presence of a high concentration of inorganic suspended particles, but some of them have not yet been tested (modified after Kirk, 1991b): (1) Decreased pumping rate of the thoracic feeding appendages (McCabe \& O'Brien, 1983). (2) Increased rejection of collected algal particles from the food groove before injection (shown by Kirk, 1991b). (3) Increased number of cells washed out of the branchial chamber before being captured by the thoracic appendages (Scavia et al., 1984; Vanderploeg et al., 1987). Additionally, ingested inorganic material caused an increase in specific weight of $D$. hyalina and, as a result, in the velocity of sinking and the frequency of antenna beats (Zurek, 1982). With higher suspended particle concentrations in the gut, it would take more energy for an individual to stay at the same depth. All these mechanisms were not particularly tested in our study, but we suppose that the high proportion of inorganic material in the nutrition of the daphnids reduces the algal ingestion rate as the animals have to filter more water to obtain their required energy ("starving with a full gut"). In our experiment, suspended particle concentrations higher than $25 \mathrm{mg}^{-1}$ seem to shift the ratio of inorganic to organic material to a disadvantageous level. Rejection of the collected algae could prevent the daphnids from ingestion of suspended particles, but as turbidity in Lake Brienz is permanent, this would then result in a reduced energy uptake, combined with a larger filtering effort.

As shown in many studies, the influence of suspended particles not only depends on the algae concentration, but also on the Daphnia species, particle type and size. In studies of Kirk (1991a) and Kirk \& Gilbert (1990), fine clay $(<1 \mu \mathrm{m})$ had no inhibitory effect on Daphnia, in contrast to coarse clay $(1-2 \mu \mathrm{m})$. In our study, over $90 \%$ of the number and over $50 \%$ of the volume of the particles were smaller than $1 \mu \mathrm{m}$. This could explain, at least in part, why particles of Lake Brienz have no negative impact on Daphnia fitness, at least in low and in situ concentrations. In some studies, the negative effect was more pronounced in small species of Daphnia (e.g., Kirk \& Gilbert, 1990). In contrast, Arruda et al. (1983) found the larger D. pulex to be more susceptible than the smaller D. parvula. Such differences might just be the consequence of the speciesspecific inter-setular spacing and therefore the filter mesh size of the filtering apparatus of Daphnia, and its interaction with the particle size.

As stated above, in treatments with low concentrations of suspended particles (up to $25 \mathrm{mg} \mathrm{l}^{-1}$ ), we could find an increased fitness of $D$. hyalina. This is confirmed by several other studies (e.g., Robinson, 1957; Kirk \& Gilbert, 1990; Hart, 1992). It is not completely clear which mechanisms are responsible for that but some untested hypotheses are: (1) Animals can feed on the organic portion other than algae of the suspended particles (Gliwicz, 1986) (in our case the fraction of organic material accounted for $1 \%$ ). (2) Suspended particles adsorb dissolved organic matter, and thus make it available for assimilation by suspension feeders (Arruda et al., 1983). At limiting food concentrations, this additional source of energy could increase the fitness of the animal. (3) Retardation of the intestinal transit rate, exposing the algae longer to the digestive enzymes, which could result in better extraction of the cell content (Maedamartinez et al., 1995). (4) Mechanical grinding of the algae in the gut by the inorganic 
particles, leading to better digestion of the food, as shown in many bird species (e.g., Gionfriddo \& Best, 1996). In our case, the proportion of organic material in the suspended particles could explain at least a part of the beneficial effect, but also other hypotheses have to be taken into account.

Recently recorded concentrations of suspended particles in Lake Brienz seem to be too low to reduce the fitness of $D$. hyalina, as the highest ever measured suspended particle concentration in the epilimnion in the centre of the lake was $24 \mathrm{mg}^{-1}$ (Finger et al., 2006). Nevertheless, during heavy rainfall or floods, concentrations could be much higher, at least temporary (several days) and in certain areas or depth layers of the lake. According to the results of our study, reproduction and growth of individuals would then be reduced, resulting in a decreased population growth. The particular time of the year when such a flood would happen is of considerable importance for the Daphnia population. In spring, algal concentrations and temperature are both low and a flood likely brings in almost pure melting water, without significant particulate organic carbon. In contrast, a flood in summer (like in September 2005, Fig. 1) occurs with a completely different background: the Daphnia population is larger, and water temperature and algae concentrations are higher. The suspended particles brought in by the river contain more organic carbon, which could, as shown in this study, be used as an additional food source. Moreover, in Lake Brienz, turbidity is not distributed evenly over the whole depth strata. The two main inflows intrude into specific depth layers, depending on the temperature of the rivers and the lake, and the particle concentration (Finger et al., 2006): In summer, maximum turbidity is found at a depth of 20-25 m. During daytime, adult daphnids in Lake Brienz stay in 25-35 m (Christian Rellstab, unpublished data). Even if daphnids would encounter much higher concentrations than $25 \mathrm{mg}^{-1}$, they would still have the possibility to avoid the most turbid layer, as they are able to perform diel vertical migration (Lampert, 1989).

In conclusion, we demonstrated that suspended particles, in combination with different food levels, have an effect on Daphnia fitness. Low concentrations of suspended particles increased fitness, while after a certain threshold $\left(25 \mathrm{mg} \mathrm{l}^{-1}\right.$ ) fitness is reduced when food concentrations were low. However, natural concentrations of suspended particles in Lake Brienz are too low to reduce the fitness of daphnids, even at very low food concentrations like in winter.

Acknowledgements Sabine Rellstab, Christine Dambone, Piotr Madej and Christoph Tellenbach helped set up and perform the experiment. Alois Zwyssig, David Finger, Mike Sturm and Erwin Grieder assisted in sampling or processing the sediment core. Richard Illi measured POC concentrations of the water samples. Bastian Bommer performed the particle size distribution measurements. Barbara Keller, Justyna Wolinska, Wayne Wurtsbaugh and two anonymous reviewers helped to improve earlier versions of this manuscript. Lisa Shama provided statistical advice. We are very grateful for their help. This study is part of the "Lake Brienz Project" and was financed by Eawag, the canton of Berne, KWO Grimselpower, BUWAL and regional communities.

\section{References}

Adalsteinsson, H., 1979. Zooplankton and its relation to available food in Lake Myvatn. Oikos 32: 162-194.

Arruda, J. A., G. R. Marzolf \& R. T. Faulk, 1983. The role of suspended sediments in the nutrition of zooplankton in turbid reservoirs. Ecology 64: 1225-1235.

Bozelli, R. L., 1998. Influences of suspended inorganic matter on carbon ingestion and incorporation rates of two tropical cladocerans, Diaphanosoma birgei and Moina minuta. Archiv für Hydrobiologie 142: 451-465.

Carvalho, M. L., 1984. Influence of predation by fish and water turbidity on a Daphnia-Gessneri population in an amazonian floodplain lake, Brazil. Hydrobiologia 113: 243-247.

Chiou, C. T., L. J. Peters \& V. H. Freed, 1979. Physical concept of soil-water equilibria for non-ionic organic-compounds. Science 206: 831-832.

Demott, W. R., 1982. Feeding selectivities and relative ingestion rates of Daphnia and Bosmina. Limnology and Oceanography 27: 518-527.

Finger, D., M. Schmid \& A. Wüest, 2006. Effects of upstream hydropower operation on riverine particle transport and turbidity in downstream lakes. Water Resources Research 42: W08429, doi:10.1029/2005WR004751.

G-Toth, L., K. V-Balogh \& N. P. Zankai, 1986. Significance and degreee of abioseston consumption in the filter-feeder Daphnia galeata Sars am. Richard (Cladocera) in Lake Balaton. Archiv für Hydrobiologie 106: 45-60.

Gionfriddo, J. P. \& L. B. Best, 1996. Grit-use patterns in North American birds: The influence of diet, body size, and gender. Wilson Bulletin 108: 685-696.

Gliwicz, M. Z., 1986. Suspended clay concentration controlled by filter-feeding zooplankton in a tropical reservoir. Nature 323: 330-332.

Hart, R. C., 1986. Zooplankton abundance, community structure and dynamics in relation to inorganic turbidity, and their implications for a potential fishery in subtropical Lake Le-Roux, South-Africa. Freshwater Biology 16: 351-371.

Hart, R. C., 1987. Population-dynamics and production of 5 crustacean zooplankters in a subtropical reservoir during 
years of contrasting turbidity. Freshwater Biology 18: 287-318.

Hart, R. C., 1992. Experimental studies of food and suspended sediment effects on growth and reproduction of 6 planktonic cladocerans. Journal of Plankton Research 14: 1425-1448.

Jewson, D. H. \& J. A. Taylor, 1978. Influence of turbidity on net phytoplankton photosynthesis in some Irish lakes. Freshwater Biology 8: 573-584.

Kirk, K. L., 1991a. Inorganic particles alter competition in grazing plankton - the role of selective feeding. Ecology 72: 915-923.

Kirk, K. L., 1991b. Suspended clay reduces Daphnia feeding rate-behavioral mechanisms. Freshwater Biology 25: 357-365.

Kirk, K. L., 1992. Effects of suspended clay on Daphnia body growth and fitness. Freshwater Biology 28: 103-109.

Kirk, K. L. \& J. J. Gilbert, 1990. Suspended clay and the population dynamics of planktonic rotifers and cladocerans. Ecology 71: 1741-1755.

Koenings, J. P., R. D. Burkett \& J. M. Edmundson, 1990. The exclusion of limnetic cladocera from turbid glacier-meltwater lakes. Ecology 71: 57-67.

Krause-Jensen, D. \& K. Sand-Jensen, 1998. Light attenuation and photosynthesis of aquatic plant communities. Limnology and Oceanography 43: 396-407.

Lampert, W., 1977. Studies on the carbon balance of Daphnia pulex as related to environmental conditions-IV. Determination of the "threshold" concentration as a factor controlling the abundance of zooplankton species. Archiv für Hydrobiologie/Supplement 48: 361-368.

Lampert, W., 1978. A field study on the dependence of the fecundity of Daphnia spec. on food concentration. Oecologia 36: 363-369.

Lampert, W., 1989. The adaptive significance of diel vertical migration of zooplankton. Functional Ecology 3: 21-28.

Lampert, W. \& I. Trubetskova, 1996. Juvenile growth rate as a measure of fitness in Daphnia. Functional Ecology 10: 631-635.

Lampert, W. \& U. Sommer, 1999, Limnoökologie. Georg Thieme Verlag. Stuttgart, New York.

Maedamartinez, A. M., H. Obregonbarboza \& H. J. Dumont, 1995. Laboratory culture of fairy shrimps using bakersyeast as basic food in a flow-through system. Hydrobiologia 298: 141-157.

Manca, M. \& D. Ruggiu, 1998. Consequences of pelagic foodweb changes during a long-term lake oligotrophication process. Limnology and Oceanography 43: 1368-1373.

McCabe, G. D. \& W. J. O'Brien, 1983. The effects of suspended silt on feeding and reproduction of Daphnia pulex. American Midland Naturalist 110: 324-337.
McCarthy, J. F., 1983. Role of particulate organic-matter in decreasing accumulation of polynuclear aromatic-hydrocarbons by Daphnia magna. Archives of Environmental Contamination and Toxicology 12: 559-568.

Müller-Navarra, D. \& W. Lampert, 1996. Seasonal patterns of food limitation in Daphnia galeata: separating food quantity and food quality effects. Journal of Plankton Research 18: 1137-1157.

Müller, B., R. Stierli \& A. Wüest, 2006. Phosphate adsorption by mineral weathering particles in oligotrophic waters of high particle content. Water Resources Research 42: W10414, doi:10.1029/2005WR004778.

Paloheimo, I. E., 1974. Calculation of instantaneous birth rate. Limnology and Oceanography 19: 692-694.

Rellstab, C., V. Maurer, M. Zeh, H. Bürgi \& P. Spaak, 2007. Temporary collapse of the Daphnia population in turbid and ultra-oligotrophic Lake Brienz. Aquatic Sciences 69: 257-270.

Robinson, M., 1957. The effects of suspended materials on the reproductive rate of Daphnia magna. Publications of the Institute of Marine Science 4: 265-277.

Scavia, D., G. L. Fahnenstiel, J. A. Davis \& R. G. Kreis, 1984. Small-scale nutrient patchiness-some consequences and a new encounter mechanism. Limnology and Oceanography 29: 785-793.

Sturm, M., 1976. Die Oberflächensedimente des Brienzersees. Eclogae Geologicae Helvetiae 69: 111-123.

Sturm, M. \& A. Matter, 1978. Turbidites and varves in Lake Brienz (Switzerland); deposition of clastic detritus by density currents. Special Publication of the International Association of Sedimentologists 2: 147-168.

Vanderploeg, H. A., B. J. Eadie, J. R. Liebig \& S. J. Tarapchak, 1987. Contribution of calcite to the particle-size spectrum of Lake Michigan seston and its interactions with the plankton. Canadian Journal of Fisheries and Aquatic Sciences 44: 1898-1914.

Vinyard, G. L. \& W. J. O’Brien, 1976. Effects of light and turbidity on reactive distance of bluegill (Lepomis macrochirus). Journal of the Fisheries Research Board of Canada 33: 2845-2849.

Zettler, E. R. \& J. C. H. Carter, 1986. Zooplankton community and species responses to a natural turbidity gradient in Lake Temiskaming, Ontario Quebec. Canadian Journal of Fisheries and Aquatic Sciences 43: 665-673.

Zurek, R., 1980. Effect of suspended materials on zooplankton-1. Natural environments. Acto Hydrobiologica 22: $449-471$.

Zurek, R., 1982. Effect of suspended materials on zooplankton-2. Laboratory investigations of Daphnia hyalina Leydig. Acto Hydrobiologica 24: 233-251. 